\title{
LITERATURE REVIEWS
}

\section{A Narrative Review of Lumbar Fusion Surgery With Relevance to Chiropractic Practice}

\author{
Clinton J. Daniels, DC, MS, Pamela J. Wakefield, DC, Glenn A. Bub, DC, and James D. Toombs, MD
}

\begin{abstract}
Objective: The purpose of this narrative review was to describe the most common spinal fusion surgical procedures, address the clinical indications for lumbar fusion in degeneration cases, identify potential complications, and discuss their relevance to chiropractic management of patients after surgical fusion.

Methods: The PubMed database was searched from the beginning of the record through March 31, 2015, for English language articles related to lumbar fusion or arthrodesis or both and their incidence, procedures, complications, and postoperative chiropractic cases. Articles were retrieved and evaluated for relevance. The bibliographies of selected articles were also reviewed.

Results: The most typical lumbar fusion procedures are posterior lumbar interbody fusion, anterior lumbar interbody fusion, transforaminal interbody fusion, and lateral lumbar interbody fusion. Fair level evidence supports lumbar fusion procedures for degenerative spondylolisthesis with instability and for intractable low back pain that has failed conservative care. Complications and development of chronic pain after surgery is common, and these patients frequently present to chiropractic physicians. Several reports describe the potential benefit of chiropractic management with spinal manipulation, flexion-distraction manipulation, and manipulation under anesthesia for postfusion low back pain. There are no published experimental studies related specifically to chiropractic care of postfusion low back pain. Conclusions: This article describes the indications for fusion, common surgical practice, potential complications, and relevant published chiropractic literature. This review includes 10 cases that showed positive benefits from chiropractic manipulation, flexion-distraction, and/or manipulation under anesthesia for postfusion lumbar pain. Chiropractic care may have a role in helping patients in pain who have undergone lumbar fusion surgery. (J Chiropr Med 2016;15:259-271)

Key Indexing Terms: Manipulation; Chiropractic; Postoperative Periods; Spinal Fusion; Surgical Procedures; Operative
\end{abstract}

\section{INTRODUCTION}

Lumbar spinal fusion procedures are commonly used treatments for an array of degenerative conditions. ${ }^{1}$ Regardless of the type of surgical intervention, up to $61 \%$ of patients continue to experience chronic spinal pain after

Veteran Affairs Saint Louis Health Care System, St. Louis, MO. Logan University, Chesterfield, MO.

The views expressed are those of the author and do not reflect the official policy of the Department of Veterans Affairs, or the US Government.

Corresponding author: Clinton J. Daniels, DC, MS, 811 Rowell St, Steilacoom, WA 98388.

(e-mail: Clinton.daniels@logan.edu).

Paper submitted October 19, 2015; in revised form June 23, 2016; accepted August 5, 2016.

$1556-3707$

(C) 2016 National University of Health Sciences.

http://dx.doi.org/10.1016/j.jcm.2016.08.007 surgery. ${ }^{2-4}$ The number of lumbar spinal surgeries has increased over the past several decades with 1288496 new posterior lumbar fusion operations reported in the United States alone between 1998 and 2008..$^{5}$ The reported prevalence of postoperative patients presenting to chiropractic clinics ranges from $2.3 \%$ to $12 \%{ }^{6-8}$ Even with the increased frequency of postoperative cases, there is limited evidence on the safety and efficacy of chiropractic care in this population.

Management of chronic degenerative spinal conditions in the United States is estimated to cost nearly $\$ 85$ billion annually, with a significant percentage attributed to the dramatic increase in the frequency of lumbar fusion procedures. ${ }^{9-11}$ In 2004, more than $\$ 16$ billion in hospital charges were attributed to over 300000 spinal fusions. ${ }^{12}$ Lumbar fusion procedures are performed for a wide array of indications, including correction of degenerative deformities, trauma, infection, tumor, and congenital anomalies, 
such as scoliosis. ${ }^{1}$ The intention of spinal fusion is to restore anatomical alignment and biomechanics to as near normalcy as possible. ${ }^{1}$ The application of these surgical fusions continues to expand as technological advances facilitate the ability to achieve a solid arthrodesis and understanding of the pathologic and biomechanical aspects of degenerative spine disease continues to progress. ${ }^{13}$

At present, there is no published article that reviews the literature on chiropractic and postfusion low back pain. Therefore, the purpose of this narrative review was to describe the most common surgical lumbar fusion procedures, address the clinical indications for lumbar fusion in degenerative cases, identify potential complications, and discuss published articles related to chiropractic management.

\section{MetHODS}

A review of the literature was performed using the PubMed database. Search terms included lumbar fusion and/ or arthrodesis and their incidence, procedures, and complications, as well as postfusion chiropractic cases. The bibliographies of articles discerned to be relevant were also reviewed. PubMed was searched in April 2015 from the beginning of the record through March 2015. English language articles as well as other article types were included in the search with no other exclusion criteria. Articles found were identified and evaluated for their relevance to lumbar fusions. Studies were selected if they reported on lumbar fusion incidence, procedures, complications, and postfusion chiropractic care.

\section{RESULTS}

One hundred-eighteen articles were selected by the authors on the basis of their relevance to lumbar fusion operative procedures, indications, complications, and postoperative chiropractic care. No articles provided a review of current management practices related to chiropractic practice for postfusion low back pain, and no articles reported a position statement on chiropractic assessment or care.

\section{DISCUSSION}

\section{Lumbar Fusion Operative Procedures}

Fusion of the spine was first depicted in the scientific literature by Albee in 1911 as a treatment for tuberculous spondylitis. ${ }^{14}$ In 1929 , Chandler was the first to use spinal fusion for the treatment of lower back pain and sciatica. ${ }^{15}$ Four years later, Mixter and Barr reported that intervention with discectomy provided relief for discogenic sciatic pain but did not relieve chronic lower back pain. ${ }^{16}$ Barr proposed discectomy in conjunction with fusion to overcome this problem. ${ }^{17}$

The first reports of an anterior approach to fusion originated in the 1930s when Ito et al. used this approach to stabilize tuberculous spondylitis. ${ }^{18}$ Early on, high rates of failure and neurovascular complications had been the major problems with this approach. ${ }^{19}$ In the meantime, anterior approaches to the lumbar spine and anterior lumbar interbody fusion (ALIF) have evolved, and the ALIF technique is now especially preferred at the lumbosacral junction. ${ }^{19}$ Anterior lumbar interbody fusion has an added advantage in that it can be combined with posterior lumbar interbody fusion (PLIF). The exposure of the anterior spine is classically performed through a left paramedial incision over the disk space to be fused. A retroperitoneal maneuver is made to expose the anterior spine. The vascular structures and the ureter are then expertly identified, commonly by a vascular surgeon, and retracted to avoid injury. Next, the anterior longitudinal ligament is incised, with special care taken to avoid injury to the hypogastric plexus. Damaged disk material and osteophytes are removed before the bony endplates can be prepared. From the anterior direction the surgeon then packs the bony graft into the implant and the surrounding disk space. Graft material most commonly comes from cadavers but can also be harvested from the patient's own iliac crest. The implant for ALIF is a single, wedge-shaped cage that has variable lordosis angles. These implants often have blades that penetrate the vertebra above and below to secure the position ${ }^{20-25}$ (Fig 1).

In 1944, Briggs and Milligan presented a technique for posterior lumbar spinal decompression and fusion ${ }^{26}$ (Figs 2 and 3). They described placement of interbody bone chips and a spinous process peg; however, they were not able to obtain successful postoperative fusion. ${ }^{27}$ In 1953, Cloward first described the PLIF technique for treatment of a ruptured disk. ${ }^{28}$ The posterior approach to reconstruction is often preferred in the lumbar spine because this causes lower morbidity compared with the anterior approach, and pedicle screws and rods or plates can be placed before dural retraction and dissection of the intervertebral disk. ${ }^{1}$ Posterior lumbar interbody fusion employs a direct posterior approach to exposure of the spine. A midline incision allows access to the disk space of interest via an open 3- to 6-inch incision or sequential tubular dilators. ${ }^{19}$ After exposure of the spine, the surgeon strips the erector spinae muscle from the lamina and sequentially performs a laminotomy, removes the ligamentum flavum, retracts nerve roots, excises damaged disk material, and performs endplate preparation. Dual ovoid-shaped spacers are then placed within the intervertebral disk space and supplemented by packed bone graft. Fluoroscopy is used to confirm the implant position, and the graft-filled space is then stabilized with pedicle screws and rods to immobilize the segment and allow fusion to occur. ${ }^{29-31}$

Transforaminal lumbar interbody fusion (TLIF) was first described by Harms and Rollinger in $1982^{32}$ (Fig 4). Transforaminal lumbar interbody fusion, which is a modified and unilateral approach to PLIF, provides more lateral access to the disk space and reduces retraction of the 

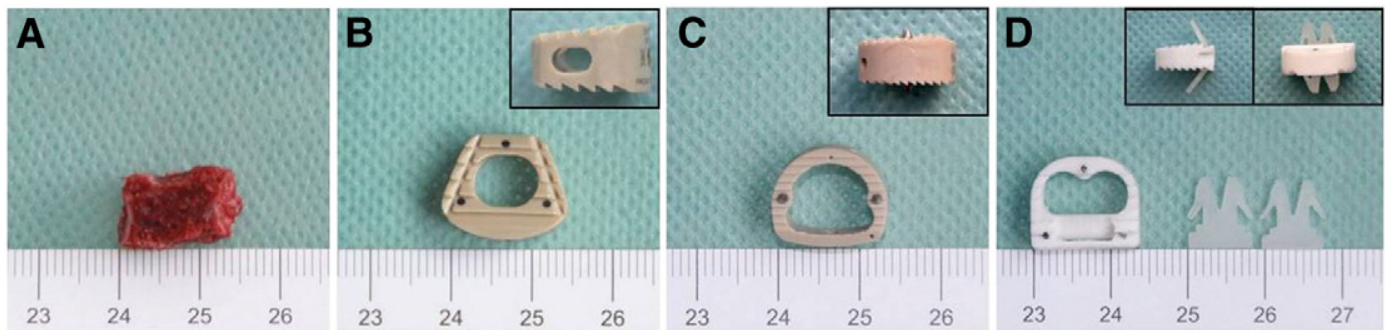

Fig I. A, Autologous bone graft obtained from anterior iliac crest. B. The Medtronic cage has a cylindrical hollow center and a flat superior surface. Inset: Lateral view of a Medtronic cage. C, Solis cage has $1 \mathrm{~mm}$ titanium spikes bilaterally on both inferior and superior surface. Inset: Lateral view of a Solis cage. D, Bioabsorbable, self-retaining cervical fusion cage, composite of an interbody fusion cage and two anchoring clips. Inset: Lateral and dorsal views and of assembled bioabsorbable, self-retaining cervical fusion cage. (Image provided by International Journal of Nanomedicine. From Cao L, Duan PG, Li XL, et al. Biomechanical stability of a bioabsorbable self-retaining polylactic acid/nano-sized B-tricalcium phosphate cervical spine interbody fusion device in single-level anterior cervical discectomy and fusion sheep models. Int J Nanomed. 2012;7:5875-5880.)

thecal sac and the nerve root. The technique was designed with the goal of achieving solid arthrodesis with minimal risk to the neural structures and avoiding the need for two-staged operations. ${ }^{19}$ Transforaminal lumbar interbody fusion exposure is achieved through a midline or paramedian incision. A transforaminal window is then created on one side by resecting the ascending articular process of the lower vertebra to the medial wall of the pedicle. This is followed by aggressive discectomy and endplate preparation; finally, the bone graft is placed anteriorly and to the

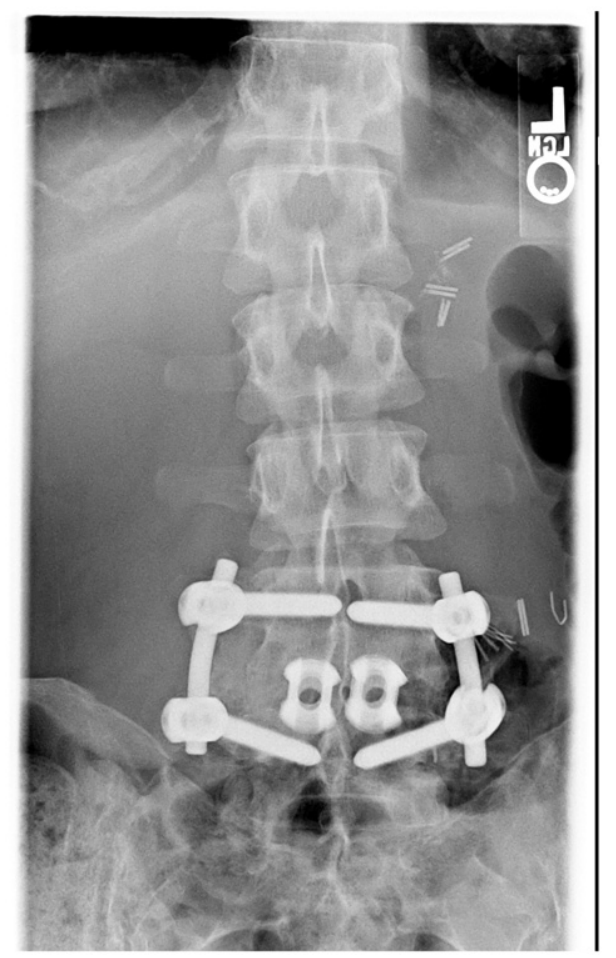

Fig 2. Posterior lumbar interbody fusion. Anteroposterior view with clear view of dual ovid spacers. (Image provided courtesy of Logan University, Department of Radiology.) contralateral side of the disk space. Once the implant is inserted and the remainder of the interspace packed with bony graft, its position is confirmed with fluoroscopy. Similar to PLIF, pedicle screws are placed and joined by rods to induce lordosis and lock the graft in place. ${ }^{29,33-36}$

Lateral lumbar interbody fusion (LLIF), also known as extreme LLIF, is a comparatively novel surgical approach for spinal fusion. ${ }^{19}$ It was developed as a minimally invasive modified technique of ALIF. ${ }^{37}$ Lateral lumbar interbody fusion begins with the patient in either the left or the right side-lying position. A small incision is made laterally allowing access of a series of dilation tubes and retractor to create a portal. Through the portal, entry can be gained to the retroperitoneal space, with the peritoneum swept anteriorly, and dissection carried through the psoas muscle. Electromyography monitoring is placed within the psoas to identify the lumbosacral plexus. A transpsoas approach is taken, and the muscle fibers are carefully separated. ${ }^{38}$ Discectomy and endplate preparation come next, immediately followed by packing of the disk space and implant with bony graft. The implant utilized most frequently in LLIF is a single, ovoid implant. Upon completion, the wounds are closed, and the patient position can then be changed to the prone position for placement of pedicle screws. ${ }^{38-40}$ Because of the minimally invasive nature of LLIF, it has the disadvantage of not allowing the use of additional hardware to stabilize the spine until fusion occurs, and it is challenging to convert to an open procedure should complications arise.

\section{Indications for Fusion}

In practice, fusion is used to manage numerous degenerative conditions. Guideline updates from the American Association of Neurological Surgeons/Congress of Neurological Surgeons suggest fair evidence (Grade B) for the use of fusion surgery to treat intractable lower back pain when conservative care has failed as well as for 


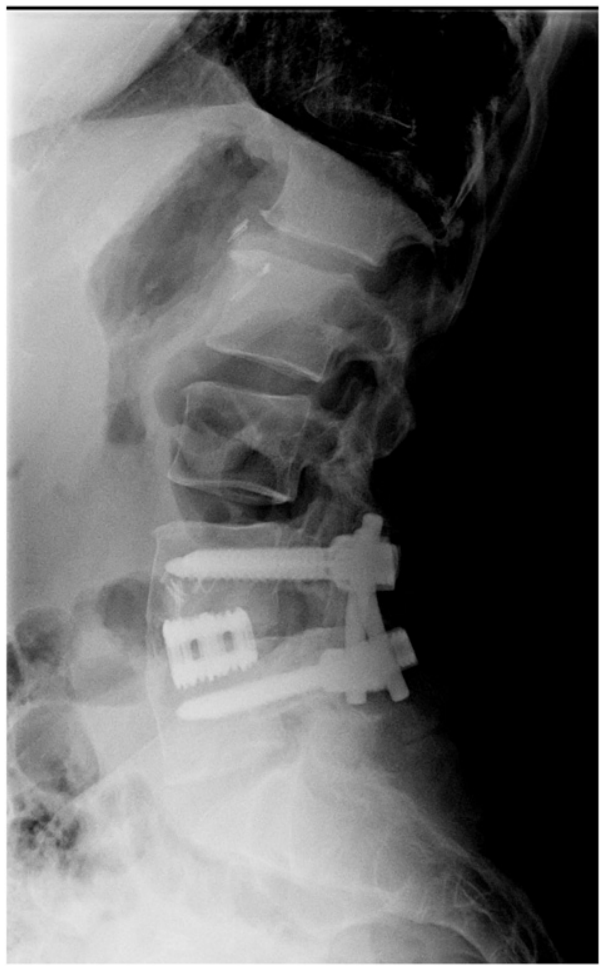

Fig 3. Posterior lumbar interbody fusion lateral. (Image provided courtesy of Logan University, Department of Radiology.)

stenosis with spondylolisthesis. ${ }^{41,42}$ There was, however, poor evidence (Grade C) in support of fusion for disk herniation with radiculopathy and for spinal stenosis without spondylolisthesis ${ }^{43,44}$ (Tables 1 and 2).

Nonspecific Low Badk Pain. Establishing an appropriate surgical treatment strategy for patients with low back pain, in the absence of stenosis or spondylolisthesis, remains a contentious topic. ${ }^{41}$ It is recommended that lumbar fusion be performed in patients whose low back pain is unresponsive to conservative treatment and is caused by level 1 or 2 degenerative disk disease without stenosis or spondylolisthesis. ${ }^{41}$ Unfortunately, conservative care in surgical studies tends to consist of a heterogeneous mixture of therapies and modalities with minimal definition of specifics or timeline. Fritzel et al. randomized 294 patients into 1 of 3 surgical groups or physical therapy and found that fusion was more successful than nonoperative care for reducing back pain and improving Oswestry Disability Index scores and return-to-work. ${ }^{45}$ Although the surgery group outperformed the physical therapy group, their outcomes were suboptimal, with only a $32.7 \%$ reduction in low back pain at 2-year follow-ups.

Two studies by Brox et al. presented parallel benefits in lumbar fusion surgery and physical therapy with cognitive exercises at 1-year follow-up. ${ }^{46,47} \mathrm{~A}$ randomized, multicenter trial by Fairbank et al. found a lack of benefit for lumbar fusion over intensive rehabilitation, and 19 of their surgical subjects experienced complications, with 11 requiring additional surgery. ${ }^{48}$ At this point, current evidence does not identify any single best treatment for uncomplicated lower back pain.

Lumbar Disk Herniation With Radiculopathy. Lumbar spinal fusion is not recommended as a routine treatment following primary disk excision in patients with isolated herniated lumbar disks causing radiculopathy. ${ }^{43}$ However, fusion appears to have better outcomes for herniated disk injuries if the patient engages in manual labor, or if there is evidence of significant chronic axial back pain, severe degenerative changes, and/or instability associated with radiculopathy. ${ }^{43}$ Reoperative discectomy with fusion is an appropriate strategy in patients with recurring herniation associated with instability or chronic axial low back pain. The routine use of fusion with simultaneous disk excision for primary lumbar herniated nucleus pulposus is not recommended. A retrospective review by Takeshima et al. found no statistically significant distinction between microdiscectomy and microdiscectomy plus fusion. ${ }^{49}$ In addition they found that $70 \%$ of the discectomy-alone group returned to work within 1 year versus only $45 \%$ in the discectomy-plus-fusion group. ${ }^{49}$ Matsunaga et al. presented a retrospective review of 80 cases, supporting the use of posterolateral fusion (PLF) at time of discectomy to improve the return-to-work rates in patents involved in heavy manual labor. ${ }^{50}$ They found that at the 1 -year point, $53 \%$ of the patients in the discectomy group
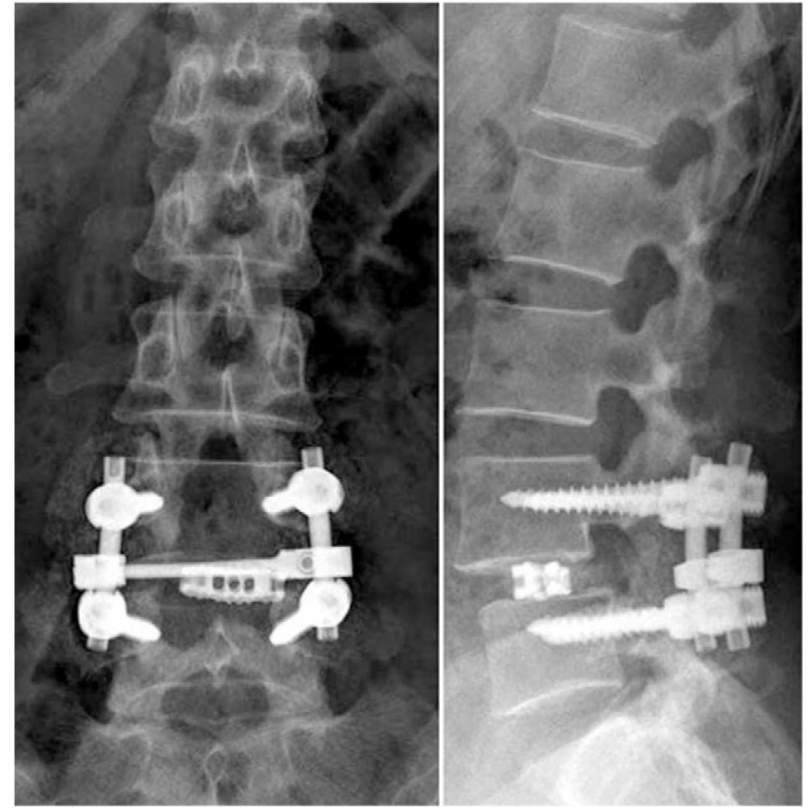

Fig 4. The postoperative plain radiographs show a successful L4 wide laminectomy and transforaminal lumbar interbody fusion of L4-5 in a patient with lumbar degenerative spondylolisthesis. (Image provided courtesy of Asian Spine Journal. From Sakai T, Sairyo K, Bhatia NN, et al. MRI changes of the spinal subdural space after lumbar spine surgeries: report of two cases. Asian Spine J. 2011;5(4):262-266.) 
and $89 \%$ of those in the fusion group were able to return to work. $^{50}$ Eie et al. reported on 259 patients with disk herniation treated with discectomy alone or noninstrumented PLF. This work supports the use of fusion at the time of discectomy in patients with severe lower back pain because there is a higher chance of having pain in later years without concomitant fusion. ${ }^{51} \mathrm{Fu}$ et al. investigated the outcome of 41 cases of recurrent lumbar disk herniation and found excellent or good clinical outcomes in $78.3 \%$ of the discectomy cohort and $83.3 \%$ of the fusion cohort. ${ }^{52}$ Chitnavis et al. treated patients with recurrent disk herniation and had good results with fusion when signs of instability and/or axial low back pain were present. ${ }^{53}$ There does not appear to be evidence to support the routine use of fusion in conjunction with discectomy. However, patients with demonstrated preoperative instability and significant chronic low back pain in addition to radicular symptoms may be candidates for fusion at the time of primary disk excision. ${ }^{42}$

Stenosis With Spondylolisthesis. Surgical decompression and fusion (Grade B evidence) are suggested for patients who have symptomatic neurogenic claudication caused by lumbar stenosis, but without myelopathy, and elect to undergo surgical intervention. ${ }^{43}$ Similarly, the North American Spine Society recommends surgical decompression with fusion for the treatment of patients with degenerative lumbar spondylolisthesis to improve clinical outcomes, preferred over decompression alone. ${ }^{54}$ The Spine Pain Outcomes Research Trial demonstrated that when patients are able to select their treatment strategy on the basis of their symptoms, values, and surgical recommendation, those who choose surgery experienced superior outcomes in every clinical measure and at every time point for at least 4 years following treatment. ${ }^{55,56}$ There is evidential support of the benefit of decompression and fusion for stenosis associated with a spondylolisthesis. ${ }^{57}$ Cheng et al. found that fusion rates were higher and instrumentation-related complication rates were lower in the PLIF group. ${ }^{58}$ Consideration of interbody techniques may be appropriate in patients with higher-grade slips. ${ }^{58}$ However, a study by Abdu et al. was not able to detect differences in outcome between different fusion cohorts. ${ }^{59}$

Table I. Level of Evidence Recommendation Grades ${ }^{a}$

\begin{tabular}{ll}
\hline Grade & Definition \\
\hline A & $\begin{array}{l}\text { Good evidence: } 2 \text { or more Level I studies } \\
\text { with consistent findings }\end{array}$ \\
B & Fair evidence: single Level I study or multiple \\
& Level II or III studies with consistent findings \\
Poor evidence: single Level II study of \\
multiple Level IV or V studies. \\
Insufficient evidence for recommendation: \\
single level III, IV, or V study; studies of \\
equivalent strength with conflicting \\
findings/conclusions
\end{tabular}

\footnotetext{
${ }^{\mathrm{a}}$ Data from Kaiser et al. ${ }^{13}$
}

Table 2. Levels of Medical Evidence for Therapeutic Study ${ }^{a}$

Therapeutic Study-Investigating the Effectiveness of Level Treatment

\begin{tabular}{|c|c|}
\hline I & $\begin{array}{l}\text { 1. Well-designed randomized controlled trial with } \\
\text { appropriate statistical analysis/reporting } \\
\text { a. No major limitations } \\
\text { b. No more than } 1 \text { minor limitation } \\
\text { 2. Systematic review of well-designed randomized } \\
\text { controlled trials with consistent findings }\end{array}$ \\
\hline \multirow[t]{2}{*}{ II } & 1. Prospective comparative study \\
\hline & $\begin{array}{l}\text { 2. Systematic review of Level II studies or } \\
\text { review of Level I studies with inconsistent findings }\end{array}$ \\
\hline III & $\begin{array}{l}\text { 1. Case-control studies } \\
\text { 2. Retrospective comparative studies } \\
\text { 3. Systematic review of Level III studies }\end{array}$ \\
\hline IV & 1. Case series \\
\hline $\mathrm{V}$ & 1. Expert opinion \\
\hline
\end{tabular}

${ }^{a}$ Data from Kaiser et al. ${ }^{13}$

Fernandez-Fairen et al. found that unilateral screw fixation was associated with similar outcomes as those with bilateral screw fixation. ${ }^{60}$ Inamdar et al. found evidence in support of PLF over PLIF. ${ }^{61}$ They demonstrated that patients in this group who were thought to have solid arthrodesis - based on dynamic radiographs - enjoyed better functional outcomes compared with patients treated with the same procedure in whom solid arthrodesis was not achieved. ${ }^{62,63}$ McGuire and Amudson et al. found that the addition of instrumentation did not improve the fusion rates. ${ }^{64}$ Fischgrund et al. reported that patients treated with pedicle screw fixation had a statistically significantly higher fusion rate $(83 \%)$ compared with those treated with noninstrumented fusion $(45 \%){ }^{62}$

Current medical evidence continues to support the role of surgery over nonoperative therapies for patents with symptomatic stenosis associated with spondylolisthesis. The vast majority of patients across these studies underwent an instrumented PLF. The achievement of solid arthrodesis is associated with superior outcomes, and, therefore, efforts to maximize the fusion potential should be considered. Although there is insufficient evidence to recommend a standard fusion technique, surgeons should consider their own experiences and the risk of complications, as well as the patient's anatomical and physiological characteristics, comorbidities, and preferences in the decision-making process. ${ }^{42}$

Stenosis Without Spondylolisthesis. Fair evidence supports surgical decompression as a recommendation for patients who have symptomatic neurogenic claudication resulting from lumbar stenosis without spondylolisthesis and elect to undergo surgical intervention. There is poor evidence in support of lumbar fusion in the absence of deformity or instability. Fusion has not been shown to improve patient outcomes in patents with isolated stenosis, and therefore it is not recommended. In the absence of spinal deformity or instability surgical decompression is typically sufficient to alleviate the symptoms of neurogenic claudication. ${ }^{44}$ 
$\mathrm{Gu}$ et al. executed a retrospective review of 81 patients who underwent surgery for lumbar stenosis with symptoms of neurogenic claudication. ${ }^{65}$ Patients were treated with either surgical decompression and posterolateral lumbar fusion or decompression and instrumented PLF with the overall success rate just over $70 \%$ in both groups. ${ }^{65}$ Jansson et al. completed a retrospective review of 9664 operations performed on patients with lumbar stenosis with 10-year follow-up and reported a reoperation rate of $11 \%{ }^{66}$ They noted that reoperation rates were lower in patients who had undergone fusion in addition to decompression, as opposed to decompression alone. Several studies have reviewed the available literature, and all concluded that in the absence of deformity or instability, the lumbar fusion procedure was not associated with improved outcomes compared with decompression alone. ${ }^{67-70}$ In the case of patients presenting with uncomplicated lumbar stenosis, the literature has consistently demonstrated the beneficial role of surgical lumbar decompression. ${ }^{44}$ In fact, the true effect of lumbar fusion for uncomplicated stenosis cannot be determined, because most, if not all, of these studies reserve lumbar fusion for those patients presenting with stenosis and an associated spondylolisthesis ${ }^{44}$ (Table 3).

Relative contraindications to lumbar fusion surgery include postoperative epidural fibrosis, active infection, conjoined nerve roots, restricted access to disk space, severe disk space collapse, severe ankylosis, subchondral sclerosis, and osteoporosis. ${ }^{71-75}$ Successive developments in orthopedic hardware have dramatically reduced the postoperative recovery period. ${ }^{1}$ Pedicle screw and rod or plate constructs have become the preferred method of instrumentation when multiple-column reconstruction is required. ${ }^{1}$ In the absence of contraindications, the documented success rates of PLIF and TLIF procedures are generally high, with reported arthrodesis rates between $77 \%$ and $100 \%{ }^{72,76,77}$

\section{Complications of Fusion}

Severe pain after surgical procedures is a major factor leading to patient dissatisfaction, delayed recovery, immobility, and prolonged hospital stay and is associated with serious complications. ${ }^{78,79}$ Utilizing the Nationwide Inpatient Sample Database, Kalanithi et al. demonstrated a 70\% increase in the rate of complications following lumbar fusion in patients over 65 years of age compared with patients between 45 and 64 years of age. ${ }^{80}$ The most common complications associated with fusion surgeries are intraoperative neurologic injury, interbody implant or bone graft migration, dural tear, infection, heterotopic ossification, postoperative radiculopathy, osteolysis, and subsidence. ${ }^{27}$ Although there have been advancements in surgical technique and technology, the incidence of residual or recurrent postoperative back pain remains high because of the influence of a multitude of factors.
In both TLIF and PLIF, the nerve roots must be retracted to gain access to the posterior disk space. Matsui et al. observed a correlation between decreased blood flow and tension placed on the nerve during retraction, and this suggests that decreased retraction time and tension lead to a lower rate of ischemic injury. ${ }^{81}$ Radiculopathy is the most commonly reported postoperative nerve injury. ${ }^{72,73,76,82,83}$ Incidental dural tears are among the most common iatrogenic injuries, with an incidence between $2 \%$ and $14 \%$, as reported in medical literature. ${ }^{27}$ Postoperative care following incidental durotomy may include 24 to 48 hours of bed rest to reduce pressure and allow dural healing.

Infection is a complication that may not manifest until much later in the postoperative course - even more than 2 years after surgery. ${ }^{84}$ Infections following fusion surgery affect up to $9 \%$ of patients. ${ }^{71-73,76,83,85}$ The most common infectious organism is Staphylococcus aureus, and risk factors include smoking, diabetes, posterior midline approach, prolonged operative time, large volume of blood loss, previous surgery, and use nonautograft bone graft alternative. ${ }^{84,86,87}$ Spinal infections are managed with thorough irrigation and debridement of necrotic tissues and use of targeted intravenous antibiotic therapy. ${ }^{27}$ Postoperative infections add approximately an estimated $\$ 29000$ in hospital cost per patient. ${ }^{88}$ Optimization of preoperative patient nutrition and smoking cessation can aid in the prevention of infection. ${ }^{89}$

Given the technical difficulties of placing instrumentation in the spine, it is inevitable that complications occasionally arise from malpositioning of hardware. ${ }^{1}$ Implant migration may occur because of lack of stability across the segment or loss of normal bone implant apposition. ${ }^{19}$ Posterior implant migration is rare, but serious complications often lead to revision surgery. Implanted hardware exists solely to provide short-term stability while fusion develops. Inadequate fixation and subsequent motion may cause the bone graft to resorb rather than be incorporated, which, in turn, puts hardware at risk of fracture. ${ }^{1}$ Pedicle screws, in particular, deserve attention because of their frequent use and proximity to sensitive neural and vascular structures. ${ }^{1}$ They are key stabilizers of posterior instrumentation, and placement is considered optimal when pedicle screws traverse the medial aspect of the pedicle and is aligned neutrally. ${ }^{90,91}$ The most common clinical complication of hardware malposition is nerve root irritation secondary to excessive medial angulation of the screw and violation of the medial bony cortex. ${ }^{1,90}$

Instrumentation failures that can be deduced from plain film radiographs include broken hardware (Fig 5), loosening of hardware (Fig 6), pseudoarthrosis, shift of bone graft cage, and postoperative discitis. Hardware loosening can be caused by osseous resorption surrounding screws and implants and is visualized as a focal lucency (Fig 7). Graft cage and/or material may herniate anteriorly or posteriorly (depending on approach used for placement) and cause neurologic compromise. 
Successful fusion permanently alters the mechanics of the spinal segments at adjacent levels. The obligatory problem in fusion is that the lost mobility of the fused segment forces additional stresses on adjacent levels of the vertebral column. ${ }^{1}$ Even in the absence of morphologic changes, increased stress from fusion may cause microtrauma to the intervertebral disks at adjacent levels, accelerating the degenerative changes in the vertebrae, ligaments, and intervertebral disks. ${ }^{1}$ Adjacent segment disease, also known as junction failure, occurs in up to $10 \%$ of patients following posterior fusion. ${ }^{92,93}$ For example, Park et al. recently showed that placement of an anterior cervical plate with its margin within $5 \mathrm{~mm}$ of the adjacent disk space increased the incidence of osteophyte formation at that level. ${ }^{94}$ It is likely that similar events occur in the lumbar spine. In the presence of chronic low-grade instability and motion, pseudoarthrosis may develop. Pseudoarthrosis represents fibrous, rather than osseous, union of the fusion complex. ${ }^{1}$ Risk factors for pseudoarthrosis include smoking, revision for previous nonunion, and long-term use of nonsteroidal anti-inflammatory drugs. ${ }^{95-97}$

The development of chronic pain after surgery is commonplace. ${ }^{98,99}$ The rate of failure following spinal surgeries is notable. ${ }^{100}$ It has been reported that about 1 in 5 patients who have undergone various surgical procedures experience severe postoperative pain or only poor to fair relief despite pain management therapies. ${ }^{99}$

\section{Considerations for Treatment of Post-Fusion Low Back Pain}

Examination and Imaging. Standard history and physical examination have limited utility for assessing the postoperative anatomy. When considering manipulative therapies for postfusion low back pain, it is likely that a chiropractic physician would first use imaging to evaluate the status of the prior lumbar fusion. Although assessment of spinal fusion often involves a multimodal approach, plain film radiography is the most commonly used modality, given its accessibility, cost, and relatively low radiation dose. ${ }^{101}$ To effectively manage postoperative patients, doctors of chiropractic should be able to not only identify successful fusion but should also be familiar with signs of instrumentation dysfunction. Comprehensive discussions of hardware malfunction are presented elsewhere, ${ }^{1,101}$ and these topics are only briefly discussed here.

Evaluating Fusion Integrity. Typically, signs of bridging bone on imaging should occur by 6 to 9 months after surgery. ${ }^{1}$ Lateral flexion and extension radiographs must show less than 3 degrees of intersegmental position change, no lucent area around the implant, minimal loss of disk height, no fracture of vertebra or hardware, no sclerotic changes in the graft, and no visible ossification in or around the graft material. ${ }^{102}$ Early-stage pseudoarthrosis may have 


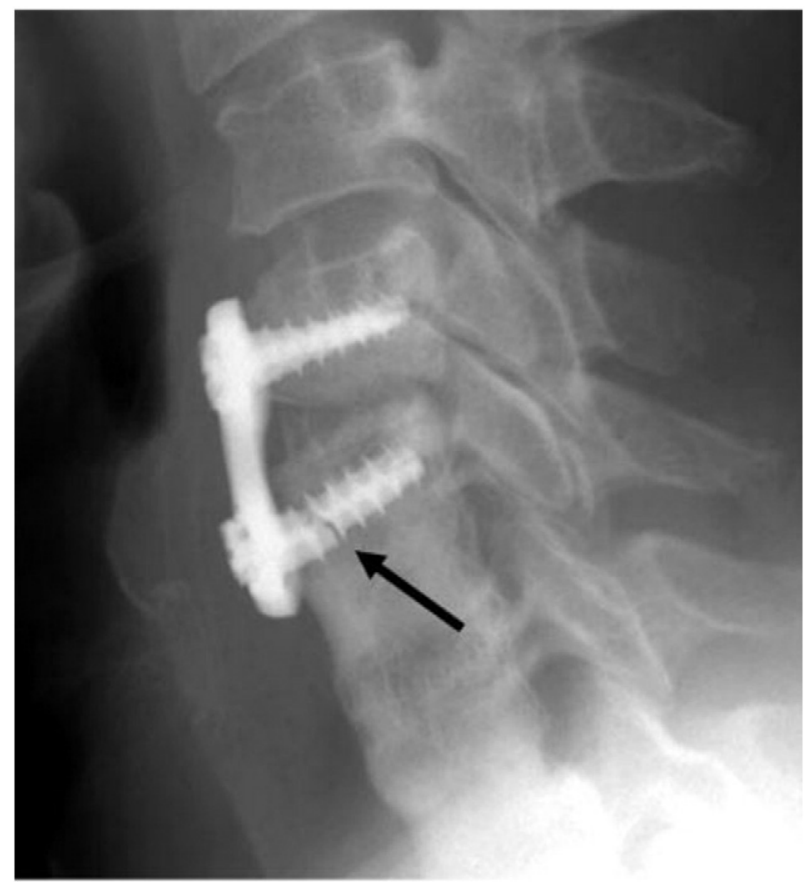

Fig 5. Extension radiograph obtained at 13-month follow-up demonstrates resorption of the graft material and fracture of the inferior screw (arrow). (Image provided courtesy of The Radiological Society of North America. From Young et al. ${ }^{1}$.)

a subtle appearance, but radionuclide bone scan or computed tomography may help confirm the diagnosis. Computed tomography or magnetic resonance imaging, or both, are the imaging modalities of choice for postoperative spine pain. In addition to evaluating for hardware failure, they are useful in the diagnosis of spondyloarthropathies, tumor, infection, sequestrated fragment, and postoperative scar or fibrosis formation. ${ }^{103}$ Intravenous contrast application is recommended in patients previously operated upon for disk herniation to help delineate postoperative scar tissue (epidural fibrosis) from herniated material. ${ }^{104}$

Chiropractic Manipulation. The available literature on the safety and effectiveness of chiropractic treatment of postoperative pain following spinal fusion is limited exclusively to case reports. Kruse and Cambron reported on the treatment of 32 postoperative cases, of which 2 were lumbar fusions treated with flexion-distraction manipulation, and with no reports of adverse events. ${ }^{105}$ In another report by Kruse and Cambron, they presented treatment of a patient with postoperative L5-S1 pain successfully managed with flexion-distraction manipulation and without any adverse events. ${ }^{106}$ Greenwood presented a single case of lumbar spine pain following an aviation crash and subsequent multiple spinal surgeries, including L3-5 fusion, which responded positively to flexion-distraction manipulation. ${ }^{107}$ McGregor and Cassidy presented 3 cases of sacroiliac syndrome following lumbar fusion, which responded to high-velocity low-amplitude (HVLA) manipulation and physical therapy modalities. ${ }^{108}$ Morningstar and Strauchman treated 3 patients with postlumbar fusion with manipulation under anesthesia followed by 8 weeks of physical therapy, reporting subjective and functional improvement without any adverse events. ${ }^{109}$ No articles reported adverse outcomes of chiropractic treatment of patients with history of lumbar fusion.

At present, there are no reports on experimental research specific to chiropractic care following fusion surgery. Furthermore, there are no published guidelines to aid chiropractic clinicians in clinical decision making for patients presenting after lumbar fusion. Frequently, studies investigating chiropractic and lower back pain specifically exclude patients with a history of spinal surgery. ${ }^{110-113}$ Large-scale randomized controlled trials are needed to effectively assess the safety and efficacy of chiropractic care for patients after lumbar fusion. Clinical trials are needed to assess the risk-to-benefit ratio of various chiropractic modalities for lumbar fusion. At this point in time, there is reason for optimism that flexion-distraction manipulation, HVLA manipulation and manipulation under anesthesia may benefit these patients. A randomized trial by Beyerman et al. provided support for the use of a combination of HVLA, flexion-distraction, and heat in the management of spinal osteoarthritis. ${ }^{114}$ It is logical that similar treatment protocols could be applied with success in postfusion cases of chronic pain with associated adjacent segment disease.

Physical Medicine and Complementary Therapies. Additional therapies such as myofascial release, rehabilitation, and acupuncture, commonly utilized by chiropractic physicians have been reported as beneficial in postoperative care following lumbar fusion. ${ }^{15-118}$ Keller indicated that after L4-5 fusion, there was modest functional improvement in hamstring length following myofascial release and massage over 7 treatment sessions. ${ }^{115}$ There is strong evidence in support of intensive rehabilitation exercise programs started 4 to 6 weeks postoperatively and no evidence that they increase reoperation rates. ${ }^{116}$ A report by Gliedt et al. stated that the stimulation of multiple body acupuncture points and auriculotherapy appear to be capable of reducing postoperative pain. ${ }^{117}$ Compared with conventional rehabilitation, electroacupuncture following lumbar fusion resulted in greater improvement in functional recovery outcomes at 3-month, 6-month, and 1-year follow-ups. ${ }^{118}$

\section{LIMITATIONS}

Our database search consisted of only a PubMed search, and we did not search the Index of Chiropractic Literature, Cumulative Index to Nursing and Allied Health Literature, or other search engines; thus, may have missed relevant articles. The methodology was not a rigorous 


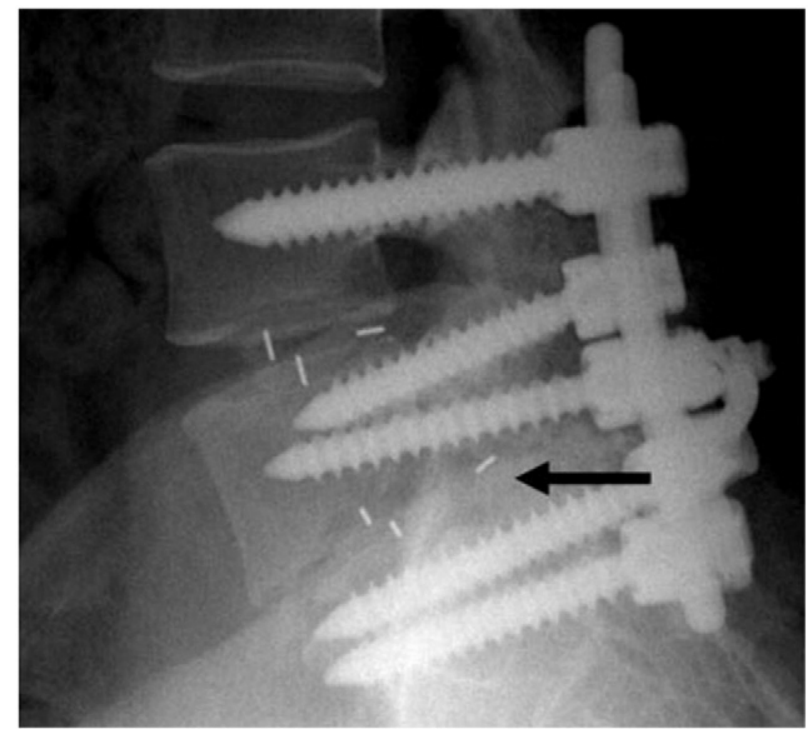

Fig 6. Lateral radiograph depicts posterior interbody fusion at L4-5 and L5-S1 and posterolateral displacement of the L5-S1 bone graft cage into the spinal canal (arrow). (Image provided courtesy of The Radiological Society of North America. From Young et al. ${ }^{l}$.)

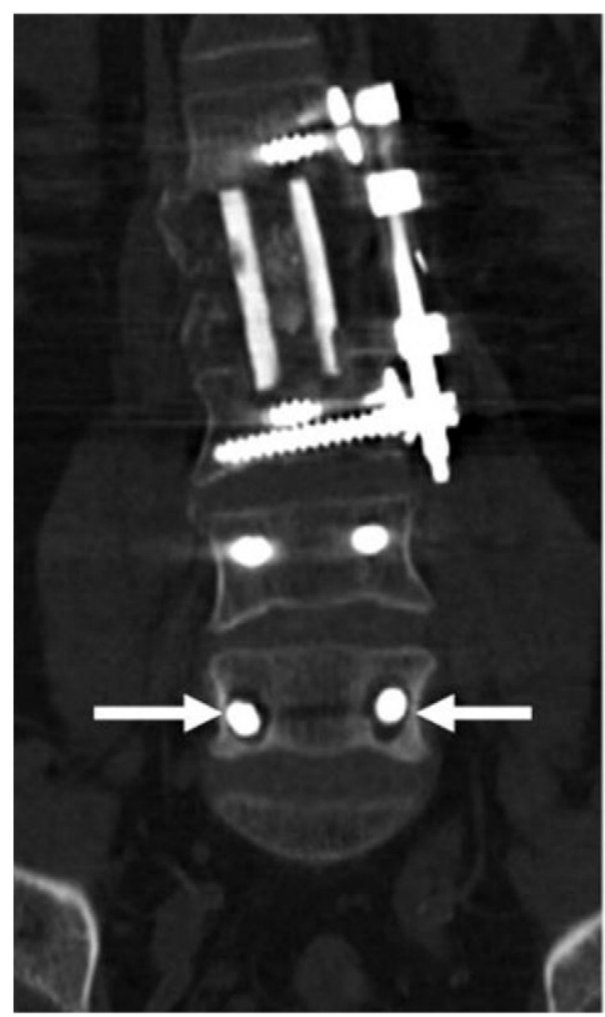

Fig 7. Coronal computed tomography image clearly shows areas of lucency around the inferior pedicle screws (arrows). (Image provided courtesy of The Radiological Society of North America. From Young et al. ${ }^{1}$.) systematic review, as we were attempting to cover several concepts related to low back pain in postfusion patients, and this would have been less feasible with a systematic approach.

\section{CONCLUSIONS}

Lumbar fusion surgeries are performed for a wide spectrum of indications, including correction of degenerative deformities, trauma, infection, tumor, and congenital anomalies, such as scoliosis. This review focused on fusion surgery for degenerative conditions and postoperative chiropractic care. For degenerative conditions, there is evidence to support the benefit of fusion in the presence of intractable low back pain for which conservative care was not successful, and for neurogenic claudication in the presence of confirmed instability with spondylolisthesis. Even with successful fusion, a large portion of patients will continue to experience significant chronic spinal pain. This review reported 10 cases with positive benefits from chiropractic manipulation, flexion-distraction, and/or manipulation under anesthesia to treat postfusion lumbar pain. Thus, chiropractic care may have a role in the treatment of patients who have undergone lumbar fusion surgery.

\section{Funding SOURCES AND CONFLICTS OF INTEREST}

No funding sources or conflicts of interest were reported for this study.

\section{CONTRIBUTORSHIP INFORMATION}

Concept development (provided idea for the research): C.J.D. C.J.D.

Design (planned the methods to generate the results):

Supervision (provided oversight, responsible for organization and implementation, writing of the manuscript): P.J.W., G.A.B

Data collection/processing (responsible for experiments, patient management, organization, or reporting data): C.J.D.

Analysis/interpretation (responsible for statistical analysis, evaluation, and presentation of the results): C.J.D., P.J.W., G.A.B., J.D.T.

Literature search (performed the literature search): C.J.D.

Writing (responsible for writing a substantive part of the manuscript): C.J.D., P.J.W., G.A.B., J.D.T.

Critical review (revised manuscript for intellectual content, this does not relate to spelling and grammar checking): P.J.W., G.A.B., J.D.T. 


\section{Practical Applications}

- Persistent pain is common following lumbar fusion procedures.

- Flexion-extension radiographs should be utilized to assess integrity of surgical fusion and rule out instability.

- Status post-fusion lumbar pain may benefit with chiropractic manipulation, flexion-distraction, or manipulation under anesthesia.

\section{REFERENCES}

1. Young PM, Berquist TH, Bancroft LW, Peterson JJ. Complications of spinal instrumentation. Radiographics. 2007;27(3): 775-789.

2. Carragee EJ, Han MY, Suen PW, Kim D. Clinical outcomes after lumbar discectomy for sciatica: the effects of fragment type and annual competence. J Bone Joint Surg Am. 2003;85(1): 102-108.

3. Maigne JY, Planchon CA. Sacroiliac joint pain after lumbar fusion. A study with anesthetic blocks. Eur Spine J. 2005;14(7): 654-658.

4. Fritsch EQ, Heisel J, Rupp S. The failed back surgery syndrome: reasons, intraoperative findings, and long-term results: a report of 182 operative treatments. Spine. 1996; 21(5):626-633.

5. Pumberger M, Chiu YL, Ma Y, Girardi FP, Mazumdar M, Memtsoudis SG. National in-hospital morbidity and mortality trends after lumbar fusion surgery between 1998 and 2008. $J$ Bone Joint Surg Br. 2012;94(3):359-364.

6. Apegren DD, Burt AL. A study of postspinal surgery cases in chiropractic offices. J Manipulative Physiol Ther. 1994;17(2): 88-92.

7. Hurwitz EL, Coulter ID, Adams AH, Genovese BJ, Shekelle PG. Use of chiropractic services from 1985 through 1991 in the United States and Canada. Am J Pub Health. 1998;88(5): 771-776

8. Stern PJ, Cote P, Cassidy JD. A series of consecutive cases of low back pain with radiating leg pain treated by chiropractors. $J$ Manipulative Physiol Ther. 1995;18(6):335-342.

9. Davis H. Increasing rate of cervical and lumbar spine surgery in the United States, 1979-1990. Spine (Phila Pa 1976). 1994; 19(10):1117-1124.

10. Deyo RA, Cherkin D, Conrad D, Volinn E. Cost, controversy, crisis: low back pain and the health of the public. Annu Rev Public Health. 1991;12:141-156.

11. Martin BI, Deyo RA, Mirza SK, et al. Expenditures and health status among adults with back and neck problems. JAMA. 2008; 299(6):656-664.

12. Deyo RA. Back surgery-who needs it? N Engl J Med. 2007; 356(22):2239-2243.

13. Kaiser MG, Eck JC, Groff MW, et al. Guideline update for the performance of fusion procedures for degenerative disease of the lumbar spine. Part 1: Introduction and methodology. $J$ Neurosurg Spine. 2014;21(1):2-6.

14. Albee FH. Transplantation of a portion of the tibia into the spine for Pott's disease: a preliminary report. JAMA. 2007;460:14-16.

15. Chandler FA. Spinal fusion operations in the treatment of low back and sciatic pain. JAMA. 1929;93:1447-1450.

16. Mixter WJ, Barr JS. Rupture of the intervertebral disc with involvements of the spinal canal. N Engl J Med. 1934;211: 210-215.

17. Barr JS. Ruptured intervertebral disc and sciatic pain. $J$ Bone Joint Surg. 1947;29(2):429-437.

18. Ito H, Tsuchiya J, Asami G. A new radical operation for Pott's disease reports of ten cases. J Bone Joint Surg. 1934;16: 499-515.

19. Talia AJ, Wong ML, Lau HC, Kaye AH. Comparison of the different surgical approaches for lumbar interbody fusion. $J$ Clin Neurosci. 2015;22(2):243-251

20. Zdeblick TAA. prospective, randomized study of lumbar fusion. Preliminary results. Spine (Phila Pa 1976). 1993;18(8) 983-991.

21. Kim Y. Finite element analysis of anterior lumbar interbody fusion: threaded cylindrical cage and pedicle screw fixation. Spine (Phila Pa 1976). 2007;32(23):2558-2568.

22. Chung SK, Lee SH, Lim SR, et al. Comparative study of laparoscopic L5-S1 fusion versus open mini-ALIF, with a minimum 2-year follow-up. Eur Spine J. 2003;12(6):613-617.

23. Dorward IG, Lenke LG, Bridwell KH, et al. Transforaminal versus anterior lumbar interbody fusion in long deformity constructs: a matched cohort analysis. Spine (Phila Pa 1976). 2013;38(12):E755-E762.

24. Kim SY, Maeng DH, Lee SH, Jang JS. Anterior lumbar interbody fusion for lumbosacral junction in steep sacral slope. $J$ Spinal Disord Tech. 2008;21(1):33-38.

25. Pellet N, Aunoble S, Meyrat R, Rigal J, Le Huec JC. Sagittal balance parameters influence indications for lumbar disc arthroplasty or ALIF. Eur Spine J. 2011;20(Suppl 5):647-662.

26. Briggs H, Milligan PR. Chip fusion of the low back following exploration of the spinal canal. J Bone Joint Surg Am. 1944; 26(1):125-130.

27. Chrastil J, Patel AA. Complications associated with posterior and transforaminal lumbar interbody fusion. $J$ Am Acad Orthop Surg. 2012;20(5):283-291.

28. Cloward RB. The treatment of ruptured lumbar intervertebral discs by vertebral body fusion. I. Indications, operative technique, after care. J Neurosurg. 1953;10(2):154-168.

29. Wiltfong RE, Bono CM, Charles Malveaux WMS, et al. Lumbar interbody fusion: review of history, complications, and outcome comparisons among methods. Curr Orthop Pract. 2012;23(3):193-202.

30. Lin PM. Posterior lumbar interbody fusion technique: complications and pitfalls. Clin Orthop Relat Res. 1985;193:90-102.

31. Cole CD, McCall TD, Schmidt MH, Dailey AT. Comparison on low back fusion techniques: transforaminal lumbar interbody fusion (TLF) or posterior lumbar interbody fusion (PLIF) approaches. Curr Rev Musculoskelet Med. 2009;2(2): $118-126$

32. Harms J, Rolinger H. A one-stage procedure in operative treatment of spondylolisthesis: dorsal traction-reposition and anterior fusion. Z Orthop Ihre Grenzgeb. 1982;120(3):343-347 [in German].

33. Beringer WF, Mobasser JP. Unilateral pedicle screw instrumentation for minimally invasive transforaminal lumbar interbody fusion. Neurosurg Focus. 2006;20(3):E4.

34. Holly LT, Schwender JD, Rouben DP, Foley KT. Minimally invasive transforaminal lumbar interbody fusion: indications, technique, and complications. Neurosurg Focus. 2006;20(3): E6.

35. Mummaneni PV, Rodts Jr GE. The mini-open transforaminal lumbar interbody fusion. Neurosurgery. 2005;57(4 Suppl): 256-261. 
36. Singh K, Vaccaro AR. Treatment of lumbar instability: transforaminal lumbar interbody fusion. Semin Spin Surg. 2005;17(4):259-266.

37. Ozgur BM, Aryan HE, Pimenta L, Taylor WR. Extreme lateral interbody fusion (XLIF): A novel surgical technique for anterior lumbar interbody fusion. Spine J. 2006;6(4):435-443.

38. Ozgur BM, Aryan HE, Pimenta L, Taylor WR. Extreme lateral interbody fusion (XLIF): a novel surgical technique for anterior lumbar interbody fusion. Spine J. 2006;6(4):435-443.

39. Shen FH, Samartzis D, Khanna AJ, Anderson DG. Minimally invasive techniques for lumbar interbody fusions. Orthop Clin North Am. 2007;38(3):373-386.

40. Shirzadi A, Birch K, Drazin D, Liu JC, Acosta Jr F. Direct lateral interbody fusion (DLIF) at the lumbosacral junction. $J$ Clin Neurosci. 2012;19(7):1022-1025.

41. Eck JC, Shran A, Ghogawala Z, et al. Guideline update for the performance of fusion procedures for degenerative disease of the lumbar spine. Part 7: Lumbar fusion for intractable low-back pain without stenosis or spondylolisthesis. J Neurosurg Spine. 2014;21(1):42-47.

42. Resnick DK, Watters WC, Sharan A, et al. Guideline update for the performance of fusion procedures for degenerative disease of the lumbar spine. Part 9: Lumbar fusion for stenosis with spondylolisthesis. J Neurosurg Spine. 2014;21(1):54-61.

43. Wang JC, Dailey AT, Mummaneni PV, et al. Guideline update for the performance of fusion procedures for degenerative disease of the lumbar spine. Part 8: Lumbar fusion for disc herniation and radiculopathy. J Neurosurg Spine. 2014;21(1): 48-53.

44. Resnick DK, Watters WC, Mummaneni PV, et al. Guideline update for the performance of fusion procedures for degenerative disease of the lumbar spine. Part 10: Lumbar fusion for stenosis without spondylolisthesis. J Neurosurg Spine. 2014; 21(1):62-66.

45. Fritzell P, Hagg O, Wessberg P, Nordwall A, Swedish Lumbar Spine Study Group. 2001 Volvo Award Winner in Clinical Studies. Lumbar fusion versus nonsurgical treatment for chronic low back pain: a multicenter randomized controlled trial from the Swedish Lumbar Spine Study Group. Spine (Phila Pa 1976). 2001;26(23):60-65.

46. Brox JI, Reikeras O, Nygaard O, et al. Lumbar instrumented fusion compared with cognitive intervention and exercises in patients with chronic low back pain after previous surgery for disc herniation: a prospective randomized controlled study. Pain. 2006;122(1-2):145-155.

47. Brox JI, Sorensen R, Friis A, et al. Randomized controlled trial of lumbar instrumented fusion and cognitive intervention and exercises in patients with chronic low back pain and disc degeneration. Spine (Phila Pa 1976). 2003;28(17):1913-1921.

48. Fairbank J, Frost H, Wilson-MacDonald J, et al. Randomised controlled trial to compare surgical stabilization of the lumbar spine with an intensive rehabilitation programme for patients with chronic low back pain: the MRC spine stabilization trial. BMJ. 2005;330(7502):1233.

49. Takeshima T, Kambara K, Miyata S, Ueda Y, Tamai S. Clinical and radiographic evaluation of disc excision for lumbar disc herniation with and without posterolateral fusion. Spine (Phila Pa 1976). 2000;25(4):450-456.

50. Matsunaga S, Sakou T, Taketomi E, Ijiri K. Comparison of operative results of lumbar disc herniation in manual laborers and athletes. Spine (Phila Pa1976). 1993;18(15):2222-2226.

51. Eie N. Comparison of the results in patients operated upon for ruptured lumbar discs with and without spinal fusion. Acta Neurochir (Wien). 1978;41(1-3):107-113.

52. TS F, Lai PL, Tsai TT, Niu CC, Chen LH, Chen WJ. Long-term results of disc excision for recurrent lumbar disc herniation with or without posterolateral fusion. Spine (Phila Pa 1976). 2005; 30(24):2830-2834.

53. Chitnavis B, Barbagallo G, Selway R, Dardis R, Hussain A, Gullan R. Posterior lumbar interbody fusion for revision disc surgery: review of 50 cases in which carbon fiber cages were implanted. J Neurosurg. 2001;95(2 Suppl):190-195.

54. Matz P, Meagher RJ, Lamer T, et al. Guideline summary review: an evidence-based clinical guideline for the diagnosis and treatment of degenerative lumbar spondylolisthesis. Spine J. 2016;16(3):439-448.

55. Weinstein JN, Lurie JD, Tosteson TD, et al. Surgical versus nonsurgical treatment for lumbar degenerative spondylolisthesis. N Engl J Med. 2007;356(22):2257-2270.

56. Weinstein JN, Lurie JD, Tosteson TD, et al. Surgical compared with nonoperative treatment for lumbar degenerative spondylolisthesis. Four-year results in the Spine Pain Outcomes Research Trial (SPORT) randomized and observational cohorts. J Bone Joint Surg Am. 2009;91(6):1295-1304.

57. Pearson AM, Lurie JD, Blood EA, et al. Spine Patient Outcomes Research Trial: radiographic predictors of clinical outcomes after operative or nonoperative treatment of degenerative spondylolisthesis. Spine (Phila Pa 1976). 2008;33(25): 2759-2766.

58. Cheng L, Nie L, Zhang L. Posterior lumbar interbody fusion versus posterolateral fusion in spondylolisthesis: a prospective controlled study in the Han nationality. Int Orthop. 2009;33(4): 1043-1047.

59. Abdu WA, Lurie JD, Spratt KF, et al. Degenerative spondylolisthesis: does fusion method influence outcome? Four-year results of the spine patient outcomes research trial. Spine (Phila Pa 1976). 2009;34(21):2351-2360.

60. Fernandez-Fairen M, Sala P, Ramirez H, Gil J. A prospective randomized study of unilateral versus bilateral instrumented posterolateral fusion in degenerative spondylolithesis. Spine (Phila Pa 1976). 2007;32(4):395-401.

61. Inamdar DN, Alagappan M, Shyam L, Devadoss S, Devadoss A. Posterior lumbar interbody fusion versus intertransverse fusion in the treatment of lumbar spondylolisthesis. $J$ Orthop Surg (Hong Kong). 2006;14(1):21-26.

62. Fischgrund JS, Mackay M, Herkowitz HN, Brower R, Montgomery DM, Kurz LT. 1997 Volvo Award Winner in Clinical Studies. Degenerative lumbar spondylolisthesis with spinal stenosis: a prospective, randomized study comparing decompressive laminectomy and arthrodesis with and without spinal instrumentation. Spine (Phila Pa 1976). 1997;22(24): 2807-2812.

63. Kornblum MB, Fischgrund JS, Herkowitz HN, Abraham DA, Berkower DL, Ditkoff JS. Degenerative lumbar spondylolisthesis with spinal stenosis: a prospective long-term study comparing fusion and pseudoarthrosis. Spine (Phila Pa 1976). 1993;29(7):726-734.

64. McGuire RA, Amundson GM. The use of primary internal fixation in spondylolisthesis. Spine (Phila Pa 1976). 2007; 18(12):1662-1672.

65. Gu Y, Chen L, Yang HL, et al. Efficacy of surgery and type of fusion in patients with degenerative lumbar spinal stenosis. $J$ Clin Neurosci. 2009;16(10):1291-1295.

66. Jansson KA, Nemeth G, Granath F, Blomqvist P. Spinal stenosis re-operation rate in Sweden is $11 \%$ at 10 years - a national analysis of 9,664 operations. Eur Spine J. 2005;14(7): 659-663.

67. Chou R, Baisden J, Carragee EJ, Resnick DK, Shaffer WO, Loeser JD. Surgery for low back pain: a review of the evidence for an American Pain Society Clinical Practice Guideline. Spine (Phila Pa 1976). 2009;34(10): 1094-1109. 
68. Gibson JN, Waddell G. Surgery for degenerative lumbar spondylosis: updated Cochrane Review. Spine (Phila Pa 1976). 2005;30(20):2312-2320.

69. Resnick DK, Choudhri TF, Dailey AT, et al. Guidelines for the performance of fusion procedures for degenerative disease of the lumbar spine. Part 10: Fusion following decompression in patients with stenosis without spondylolisthesis. J Neurosurg Spine. 2005;2(6):686-691.

70. Watters III WC, Baisden J, Gilbert TJ, et al. Degenerative lumbar spinal stenosis: an evidence-based clinical guideline for the diagnosis and treatment of degenerative lumbar spinal stenosis. Spine J. 2008;8(2):305-310.

71. Chen Z, Zhao J, Liu A, Yuan J, Li Z. Surgical treatment of recurrent lumbar disc herniation by transforaminal lumbar interbody fusion. Int Orthop. 2009;33(1):197-201.

72. Crandall DG, Revella J. Transforaminal lumbar interbody fusion versus anterior lumbar interbody fusion as an adjunct to posterior instrumented correction of degenerative lumbar scoliosis: three year clinical and radiographic outcomes. Spine (Phila Pa 1976). 2009;34(20):2126-2213.

73. Xu H, Tang H, Li Z. Surgical treatment of adult degenerative spondylolisthesis by instrumented transforaminal lumbar interbody fusion in the Han nationality. J Neurosurg Spine. 2009; 10(5):496-499.

74. Janssen ME, Lam C, Beckham R. Outcomes of allogenic cages in anterior and posterior lumbar interbody fusion. Eur Spine $J$. 2001;10(Suppl 2):5158-5168.

75. Kim KT, Lee SH, Lee YH, Bae SC, Suk KS. Clinical outcomes of 3 fusion methods through the posterior approach in the lumbar spine. Spine (Phila Pa 1976). 2006;31(12): 1351-1357.

76. Faundez AA, Schwender JD, Safriel Y, et al. Clinical and radiological outcome of anterior-posterior fusion versus transforaminal lumbar interbody fusion for symptomatic disc degeneration: a retrospective comparative study of 133 patients. Eur Spine J. 2009;18(2):203-211.

77. Rihn JA, Patel R, Makda J, et al. Complications associated with single level transforminal lumbar interbody fusion. Spine $J$. 2009;9(8):623-629.

78. Katz J, Seltzer Z. Transition from acute to chronic postsurgical pain: risk factors and protective factors. Expert Rev Neurother. 2009;9(5):723-744.

79. Kehlet H, Jensen TS, Woolf CJ. Persistent postsurgical pain: risk factors and prevention. Lancet. 2006;367(9522): 1618-1625.

80. Kalanithi PS, Patil CG, Boakye M. National complication rates and disposition after posterior lumbar fusion for acquired spondylolisthesis. Spine (Phila Pa 1976). 2009;34(18): 1963-1969.

81. Matsui H, Kitagawa H, Kawaguchi Y, Tsuji H. Physiologic changes of nerve root during posterior lumbar discectomy. Spine (Phila Pa 1976). 1995;20(6):654-659.

82. Mehta VA, McGirt MJ, Garces Ambrossi GL, et al. Transforaminal versus posterior lumbar interbody fusion: comparison of surgical morbidity. Neurol Res. 2011;33(1):38-42.

83. Villavicencio AT, Burneikiene S, Rocca CM, Nelson EL, Mason A. Minimally invasive versus open transforaminal lumbar interbody fusion. Surg Neurol Int. 2010.

84. Richards BS. Delayed infections following posterior spinal instrumentation for the treatment of idiopathic scoliosis. $J$ Bone Joint Surg Am. 1995;77(4):524-526.

85. Peng CW, Yue WM, Poh SY, Yeo W, Tan SB. Clinical and radiological outcomes of minimally invasive versus open transforaminal lumbar interbody fusion. Spine (Phila Pa 1976). 2009;34(13):1385-1389.
86. Olsen MA, Nepple JJ, Riew KD, et al. Risk factors for surgical site infection following orthopedic spinal operations. $J$ Bone $J$ Surg Am. 2008;90(1):62-69.

87. Fang A, SS H, Endres N, Bradford DS. Risk factors for infection after spinal surgery. Spine (Phila Pa 1976). 2005;30(12): 1460-1465.

88. Parker SL, Adogwa O, Wtham TF, Aaronson QS, Cheng J, McGirt MJ. Post-operative infection after minimally invasive versus open transforaminal lumbar interbody fusion (TLIF): literature review and cost analysis. Minim Invasive Neurosurg. 2011;54(1):33-37.

89. Veeravagu A, Patil CG, Lad SP, Boakye M. Risk factors for postoperative spinal wound infections after spinal decompression and fusion surgeries. Spine. 2009;34(17):1869-1872.

90. Berquist TH. Imaging of the postoperative spine. Radiol Clin North Am. 2006;44(3):407-418.

91. Rutherford EE, Tarplett LJ, Davies EM, Harley JM, King LJ. Lumbar spine fusion and stabilization: hardware, techniques, and imaging appearances. Radiographics. 2007;27(6): 1737-1749.

92. Cho KJ, Suk SI, Park SR, et al. Complications in posterior fusion and instrumentation for degenerative lumbar scoliosis. Spine (Phila Pa 1976). 2002;27(7):776-786.

93. Etebar S, Cahill DW. Risk factors for adjacent-segment failure following lumbar fixation with rigid instrumentation for degenerative instability. J Neurosurg. 1999;90(Suppl 2):163-169.

94. Park JB, Cho YS, Riew KD. Development of adjacent-level ossification in patients with an anterior cervical plate. $J$ Bone Joint Surg Am. 2005;87(3):558-563.

95. Slone RM, MacMillian M, Montgomery WJ. Spinal fixation. Part 3. Complications of spinal instrumentation. Radiographics. 1993;13(4):797-816.

96. Foley MJ, Calenoff L, Hendrix RW, Schafer MF. Thoracic and lumbar spine fusion: postoperative radiologic evaluation. AJR Am J Roentgenol. 1983;141(2):373-380.

97. Yazici M, Asher MA, Hardacker JW. The safety and efficacy of Isola-Galveston instrumentation and arthrodesis in the treatment of neuromuscular spinal deformities. J Bone Joint Surg Am. 2000;82(4):524-543.

98. Dolin SJ, Cashman JN, Bland JM. Effectiveness of acute postoperative pain management: I. Evidence from published data. Br J Anaesth. 2002;89(3):409-423.

99. Perkins FM, Kehlet H. Chronic pain as an outcome of surgery: a review of predictive factors. Anesthesiology. 2000;93(4): 1123-1133.

100. Hussain A, Erdek M. Interventional pain management for failed back surgery syndrome. Pain Pract. 2014;14(1):64-78.

101. Venu V, Vertinsky AT, Malfair D, et al. Plain radiograph assessment of spinal hardware. Semin Musculoskelet Radiol. 2011;15(2):141-162.

102. Ray CD. Threaded fusion cages for lumbar interbody fusions: an economic comparison with 360 degrees fusions. Spine. 1997.

103. Walker BE. Failed back surgery syndrome. Comsig Rev. 1992; 1(1):3-6.

104. Weiss T, Treisch J, Kazner E, Kohler D, Collmann H, Claussen CCT. of the postoperative lumbar spine: the value of intravenous contrast. Neuroradiology. 1986;28(3):241-245.

105. Kruse RA, Cambron J. Chiropractic management of postsurgical lumbar spine pain: a retrospective study of 32 cases. $J$ Manipulative Physiol Ther. 2011;34(6):408-412.

106. Kruse RA, Cambron J. Cox decompression chiropractic manipulation of a patient with post-surgical lumbar fusion: a case report. J Chiropr Med. 2011;10(4):255-260.

107. Greenwood DM. Improvement in chronic low back pain in an aviation crash survivor with adjacent segment disease following 
flexion distraction therapy: a case study. J Chiropr Med. 2012; 11(4):300-305.

108. McGregor M, Cassidy JD. Post-surgical sacroiliac joint syndrome. J Manipulative Physiol Ther. 1983;6(1):1-11.

109. Morningstar MW, Struchman MN. Manipulation under anesthesia for patients with failed back surgery: retrospective report of 3 cases with 1-year follow-up. J Chiropr Med. 2012;11(1):30-35.

110. Bishop PB, Quon JA, Fisher CG, Dvorak MF. The Chiropractic Hospital-based Interventions Research Outcomes (CHIRO) study: a randomized controlled trial on the effectiveness of clinical practice guidelines in the medical and chiropractic management of patients with acute mechanical low back pain. Spine J. 2010;10(12):1055-1064.

111. Senna MK, Machaly SA. Does maintained spinal manipulation therapy for chronic nonspecific low back pain result in better longterm outcome? Spine (Phila Pa 1976). 2011;36(18):1427-1437.

112. Walker BF, Hebert JJ, Stomski NK, et al. Outcomes of usual chiropractic. The OUCH Randomized Controlled Trial of Adverse Events. Spine (Phila Pa 1976). 2013;38(20):1723-1729.

113. Goertz CM, Xia T, Long CR, et al. Effects of spinal manipulation on sensorimotor function in low back pain patients - a randomized controlled trial. Man Ther. 2016;21: 183-190.

114. Beyerman KL, Palmerino MB, Zohn LE, Kane GM, Foster KA. Efficacy of treating low back pain and dysfunction secondary to osteoarthritis: chiropractic care compared with moist heat alone. J Manipulative Physiol Ther. 2006;29(2):107-114.

115. Keller G. The effects of massage therapy after decompression and fusion surgery of the lumbar spine: a case study. Int $J$ Massage Bodywork. 2012;5(4):3-8.

116. Ostelo RW, de Vet HC, Waddell G, Kerckhoffs MR, Leffers P, van Tulder M. Rehabilitation following first-time lumbar disc surgery: a systematic review within the framework of the Cochrane Collaboration. Spine (Phila Pa 1976). 2003;28(3): 209-218.

117. Gliedt JA, Daniels CJ, Wuollet A. Narrative review of perioperative acupuncture for clinicians. J Acupunct Meridian Stud. 2015;8(5):264-269.

118. Bin-xiu Z, Kun-zheng W, Jie-xiu Z, Chun-sheng W, Xiang-hui $\mathrm{H}$, Shu-qiang M. Clinical effects of acupuncture after surgical operation in patients with prolapse of the lumbar intervertebral disc. J Trad. Chin Med. 2008;28(4):250-254. 